\title{
ANALISIS PARTISIPASI MASYARAKAT DALAM PROGRAM PENGENDALIAN VEKTOR DBD
}

\author{
Novia Wirna Putri ${ }^{1}$, Sevilla Ukhtil Huvaid ${ }^{2}$ \\ ${ }^{1,2}$ Fakultas Kesehatan Masyarakat Universitas Baiturrahmah \\ Email: ${ }^{1}$ noviawirna.skm@gmail.com, ${ }^{2}$ sevillaukhtilhuvaid@ fkm.unbrah.ac.id
}

\begin{abstract}
Abstrak
Demam Berdarah Dengue (DBD) menjadi salah satu masalah utama penyakit menular diIndonesia. Tujuan penelitian ini adalah untuk menganalisis partisipasi masyarakat dalam program pengendalian vektor DBD. Jenis penelitian yang digunakan yaitu penelitian analitik dengan menggunakan desain cross sectional. Sampel berjumlah 99 orang yang diambil dengan teknik proportional random sampling. Analisis data meliputi analisis univariat dan bivariat. Hasil penelitian menunjukkan bahwa 52,5 \% rumah responden positif jentik, 32,3\% responden tergolong dalam kategori buruk melakukan modifikasi lingkungan, 58,6 \% responden tergolong dalam kategori buruk melakukan manipulasi lingkungan, 30,3\% responden tergolong dalam kategori buruk melakukan pengendalian fisik, sebesar 78,8\% responden tergolong dalam kategori buruk melakukan pengendalian kimiawi, dan 35,4\% responden tergolong dalam kategori buruk melakukan pengendalian biologi dalam program pengendalian vektor DBD. Hasil analisis bivariat menunjukkan bahwa terdapat hubungan yang siginifikan antara variabel modifikasi lingkungan, manipulasi lingkungan, pengendalian fisik, pengendalian kimiawi, pengendalian biologi dengan keberadaan jentik dalam program pengendalian vektor DBD. Oleh sebab itu, perlu disosialisasikan lebih lanjut kepada masyarakat mengenai program pengendalian vektor DBD baik dalam aspek modifikasi lingkungan, manipulasi lingkungan, pengendalian fisik, kimia dan biologi.
\end{abstract}

Kata kunci : DBD, lingkungan, vektor

\begin{abstract}
Dengue Hemorrhagic Fever (DHF) is one of the main problems of infectious diseases in Indonesia. The purpose of this study was to analyze community participation in the DHF vector control program. The type of research used was analytical research using a cross sectional design. The sample is 99 people taken by proportional random sampling. Data analysis included univariate and bivariate analysis. The results showed that $52.5 \%$ of respondents were larvae positive, $32.3 \%$ of respondents belonged to the bad category of environmental modification, $58.6 \%$ of respondents belong to the bad category of environmental manipulation, $30.3 \%$ of respondents belong to the bad category of controlling physically, $78.8 \%$ of respondents belong to the bad category of chemical control, and $35.4 \%$ of
\end{abstract}


respondents belong to the bad category of biological control in the DHF vector control program. The results of bivariate analysis showed that there was a significant relationship between the variables of environmental modification, environmental manipulation, physical control, chemical control, biological control with the presence of larvae in the DHF vector control program. Therefore, it needs to be further socialized to the public regarding DHF vector control programs both in aspects of environmental modification, environmental manipulation, physical, chemical and biological control.

Keywords: DHF, environment, vector

\section{PENDAHULUAN}

Demam Berdarah Dengue (DBD) adalah penyakit yang disebabkan oleh empat serotipe virus dengue yang ditularkan melalui gigitan nyamuk terinfeksi khususnya nyamuk Aedes aegypti yang terdapat hampir di seluruh pelosok Indonesia (Adrianto dkk., 2014). Pada tahun 2015, di Indonesia jumlah penderita DBD yang dilaporkan sebanyak 129.650 kasus dengan jumlah kematian sebanyak 1.071 kasus (Incidence Rate $(\mathrm{IR})=50,75$ per 100.000 penduduk dan Case Fatality Rate $=0,83 \%$ (Kementerian Kesehatan RI, 2016).

Kota Padang merupakan salah satu daerah endemis DBD di Propinsi Sumatera Barat dan tidak ada satu kecamatanpun yang bebas dari DBD. Puskesmas Air Dingin merupakan salah satu puskesmas di Kota Padang yang mengalami peningkatan kasus Demam Berdarah cukup signifikan. Pada tahun 2013 IR DBD Puskesmas Air Dingin sebesar 177,95 per 100.000 penduduk, kemudian turun di tahun $2014 \mathrm{IR}=80,8$ per 100.000 penduduk, dan di tahun 2015 mengalami peningkatan yaitu sebesar IR= 361,5 per 100.000 penduduk. Wilayah kerja Puskesmas Air Dingin meliputi tiga kelurahan yaitu Kelurahan Balai Gadang, Aia Pacah, dan Lubuk Minturun Sungai Lareh (Dinkes Kota Padang, 2016).
Untuk memutus mata rantai penularan penyakit DBD, pemerintah bersama masyarakat harus melakukan upaya pencegahan DBD. Pencegahan DBD masih diutamakan pada pengendalian vektor karena sampai saat ini masih belum tersedia vaksin dan obat antivirus yang efektif (Mulyatno dkk., 2012)

Keterlibatan masyarakat dalam program pengendalian populasi nyamuk Ae. aegypti sebagai vektor DBD sangat menentukan keberhasilan dalam upaya memperkecil terjadinya penularan DBD (Syatriani dkk., 2009). Partisipasi masyarakat dapat dilihat dari kegiatan pengendalian vektor seperti modifikasi lingkungan, manipulasi lingkungan, pengendalian fisik, pengendalian kimia, dan pengendalian biologi (Prasetyowati, 2015).

Penelitian sebelumnya terkait dengan partisipasi masyarakat belum ada dilakukan di Wilayah Kerja Puskesmas Air Dingin. Berdasarkan hal di atas maka tujuan dilakukannya penelitian ini adalah untuk menganalisis partisipasi masyarakat dalam program pengendalian vektor DBD di wilayah kerja Puskesmas Air Dingin Kota Padang tahun 2018.

\section{METODE PENELITIAN}

Jenis penelitian ini adalah penelitian analitik dengan menggunakan desain 
cross sectional. Sampel berjumlah 99 orang yang diambil dengan teknik proportional random sampling. Analisis data meliputi analisis univariat tentang partisipasi masyarakat dalam pengendalian vektor yaitu modifikasi lingkungan, manipulasi lingkungan, pengendalian fisik, pengendalian kimia, pengendalian biologi, dan keberadaan jentik di wilayah kerja Puskesmas Air Dingin serta analisis bivariat untuk melihat hubungan antara variabel modifikasi lingkungan, manipulasi lingkungan, pengendalian fisik, pengendalian kimiawi, pengendalian biologi dengan keberadaan jentik dalam program pengendalian vektor DBD. Penelitian dilakukan pada tahun 2018 di wilayah kerja Puskesmas Air Dingin yang meliputi tiga kelurahan yaitu Kelurahan Balai Gadang, Air Pacah, dan Lubuk Minturun Sungai Lareh.

\section{HASIL DAN PEMBAHASAN}

\section{Analisis Univariat}

Analisis univariat dilakukan terhadap masing-masing variabel yang diteliti dengan tabel distribusi frekuensi disertai penjelasan yaitu distribusi frekuensi partisipasi masyarakat yang meliputi modifikasi lingkungan, manipulasi lingkungan, pengendalian fisik, pengendalian kimia, pengendalian biologi, dan keberadaan jentik serta variabel keberadaan jentik.

\section{a. Modifikasi Lingkungan}

Modifikasi lingkungan adalah suatu transformasi fisik permanen (jangka panjang) terhadap tanah, air, dan tumbuh tumbuhan untuk mencegah/ menurunkan habitat jentik tanpa mengakibatkan kerugian bagi manusia. Hasil penelitian menunjukkan bahwa dari 99 responden, terdapat $32,3 \%$ responden yang tergolong dalam kategori buruk dalam melakukan modifikasi lingkungan.
Hal ini menunjukkan bahwa aspek modifikasi lingkungan dalam program pengendalian vektor DBD belum berjalan sepenuhnya. Masih ada responden yang menyatakan bahwa mereka belum mendapatkan penjelasan tentang program pengendalian vektor DBD baik secara lisan maupun tulisan dari petugas kesehatan. Menurut analisa peneliti, promosi kesehatan pada dasarnya sudah dilakukan oleh pihak puskesmas, hanya saja kurangnya frekuensi penyuluhan, belum lengkapnya materi penyuluhan, dan tidak tepatnya waktu kunjungan menyebabkan masih adanya sasaran masyarakat yang belum mendapatkan pemaparan dan penjelasan terkait program penaggulangan DBD, khususnya dalam hal pengendalian vektor DBD. Selain itu, media promosi kesehatan dalam bentuk tulisan, juga belum terdistribusi dengan baik. Oleh sebab itu, perlu adanya peningkatan peran kader jumantik dalam mengimplementasikan program penanggulangan DBD di masyarakat. Dukungan dan perhatian dari pemerintah setempat juga sangat dibutuhkan dalam mengimplementasikan program penanggulangan DBD.

\section{b. Manipulasi Lingkungan}

Manipulasi lingkungan adalah suatu pengkondisian sementara yang tidak menguntungkan atau tidak cocok sebagai tempat berkembang biak vektor penular penyakit pada habitatnya. Hasil penelitian menunjukkan bahwa dari 99 responden, terdapat 58,6\% responden yang tergolong dalam kategori buruk di dalam melakukan manipulasi lingkungan.

Hal ini menunjukkan bahwa aspek manipulasi lingkungan dalam program pengendalian vektor DBD juga belum berjalan dengan baik. Masih ada 12,1\% responden yang menyatakan bahwa mereka tidak menguras bak mandi seminggu sekali, dan $29,3 \%$ responden menyatakan bahwa mereka tidak pernah mendapatkan informasi tentang 
pengendalian DBD melalui cara manipulasi lingkungan baik dari dinas kesehatan maupun puskesmas setempat.

Menurut analisa peneliti, ketidaktahuan masyarakat tentang upaya upaya pengendalian vektor DBD secara spesifik membuat mereka masih ada yang tergolong dalam kategori tidak melakukan upaya manipulasi lingkungan. Promosi kesehatan yang dipaparkan secara umum oleh pihak puskesmas, membuat masyarakat tidak paham benar dan kurang menyadari pentingnya penerapan manipulasi lingkungan dalam upaya pengendalian vektor DBD. Oleh sebab itu perlu dilakukan peninjauan kembali terhadap substansi promosi kesehatan yang akan diberikan oleh tenaga kesehatan kepada masyarakat. Selain itu, kunjungan ke rumah - rumah masyarakat melalui sistem door to door untuk peningkatan pengetahuan dan pengawasan oleh kader jumantik dan pihak puskesmas juga harus lebih digiatkan, agar masyarakat lebih memahami dan merasa diawasi didalam melakukan upaya pengendalian vektor DBD demi keberhasilan program penanggulangan DBD.

\section{c. Pengendalian Fisik}

Pengendalian secara fisik adalah pengendalian untuk mengurangi atau menghindari gigitan nyamuk atau gangguan nyamuk dilakukan dengan pemasangan kawat kasa (kawat nyamuk) pada semua lubang yang ada di rumah, seperi lubang angin, jendela, pintu dan lainnya. Hasil penelitian menunjukkan bahwa dari 99 responden, terdapat 30,3\% responden yang tergolong dalam kategori buruk di dalam melakukan pengendalian fisik.

Menurut analisa peneliti, hal ini dapat terjadi karena kurangnya pengawasan dari petugas kesehatan yang datang memeriksa jentik dirumah atau dilingkungan mereka, begitu juga dengan himbauan terkait program pengendalian vektor DBD yang disampaikan kepada masyarakat, masih ada responden menyatakan bahwa tidak ada himbauan yang disampaikan oleh petugas baik mengenai kasus maupun terkait program pengendalian yang harus mereka lakukan. Seharusnya para pelaksana program mempunyai sikap positif dan memberikan dukungan penuh terhadap implementasi kebijakan program, sehingga terdapat kemungkinan yang besar implementasi kebijakan akan terlaksana sesuai dengan harapan. Oleh sebab itu, perlu adanya pelatihan yang diberikan kepada para pelaksana, agar mereka tahu dan memahami apa yang menjadi kewajiban mereka. Selain itu diperlukan juga evaluasi terhadap para pelaksana dalam meningkatkan partisipasi masyarakat pada program penanggulangan DBD.

\section{d. Pengendalian Kimiawi}

Pengendalian vektor secara kimiawi dapat ditempuh dengan dua teknik untuk pengendalian secara kimiawi, yaitu pengasapan (fogging) dengan menggunakan senyawa kimia malathion dan fenthion, yang berguna untuk mengurangi penularan sampai batas waktu tertentu, dan pemberantasan larva nyamuk dengan zat kimia (abate). Hasil penelitian menunjukkan bahwa pengendalian kimiawi pada kategori buruk sebesar $78,8 \%$ dan pada kategori baik sebesar $21,2 \%$ dalam partisipasi masyarakat terhadap program pengendalian vektor DBD.

Masyarakat di Wilayah Kerja Puskesmas Air Dingin sangat jarang menggunakan obat anti nyamuk. Sebanyak $9,1 \%$ masyarakat menggunakan obat nyamuk bakar, dan hanya $2 \%$ yang menggunakan obat nyamuk semprot dan oles. Adapun bentuk partisipasi masyarakat dalam upaya pengendalian kimiawi yaitu mengizinkan petugas kesehatan melakukan fogging (pengasapan). 
Rendahnya partisipasi masyarakat terjadi karena kurangnya kesadaran masyarakat untuk melakukan upaya pengendalian kimiawi seperti menggunakan bubuk abate pada bak penampungan air dan menggunakan obat anti nyamuk. Selain itu, rendahnya peran petugas kesehatan dalam mensosialisasikan penaburan bubuk abate karena masyarakat mengaku bahwa petugas kesehatan tidak pernah membagikan bubuk abate.

Upaya pengendalian kimiawi dilakukan untuk memberantas nyamuk dewasa maupun dalam bentuk larva dan pupa. Untuk nyamuk dewasa dilakukan dengan cara pengasapan (thermal fogging) atau pengabutan (cold fogging) dengan berbagai jenis insektisida misalnya golongan organophospat atau pyrethroid synthetic. Untuk pemberantasan larva nyamuk dapat menggunakan abate $1 \%$ SG. Cara ini biasanya digunakan dengan menaburkan bubuk abate ke dalam bejana tempat penampungan air seperti bak mandi, tempayan, drum dapat mencegah adanya jentik selama 2-3 bulan (Tairas, 2015).

Seharusnya petugas kesehatan membagikan dan menjelaskan cara penggunaan bubuk abate kepada masyarakat Wilayah Kerja Puskesmas Air Dingin yang merupakan daerah endemis DBD di Kota Padang. Selain itu juga memberikan informasi terkait penggunaan obat anti nyamuk yang sesuai dengan petunjuk penggunaan agar tidak menimbulkan bahaya keracunan pada manusia ataupun resistensi pada nyamuk

\section{e. Pengendalian Biologi}

Hasil penelitian menunjukkan bahwa pengendalian secara biologi pada kategori buruk sebesar $35,4 \%$ dan pada kategori baik sebesar $64,6 \%$ dalam partisipasi masyarakat terhadap program pengendalian vektor DBD. Berdasarkan hasil distribusi frekuensi jawaban responden dari kuesioner pengendalian biologi, ditemukan sebanyak 30,3\% tidak mendapatkan informasi tentang pengendalian DBD secara biologi dari dinak kesehatan/puskesmas.

Partisipasi masyarakat dalam upaya pengendalian biologi sudah cukup baik. Sebanyak $91,9 \%$ responden menanam tanaman pengusir nyamuk seperti serai wangi, kincung dan ruku-ruku di pekarangan rumahnya. Masyarakat sudah banyak mendapatkan informasi dari dinas kesehatan/puskesmas terkait dengan pengendalian biologis $(69,7 \%)$.

Pengendalian larva Aedes aegypti secara biologi atau hayati menggunakan organisme yang dalam pengendalian secara hayati umumnya bersifat predator, parasitik atau patogenik. Beberapa agen hayati yang digunakan untuk memberantas nyamuk Aedes aegypti seperti ikan kepala timah (Aplocheilus panchax), ikan nila (Oreochronis nilocitus), ikan guppy (Poecilia reticulata), ikan mujair (Oreochronis mossambicus), ikan cupang (Betta splendens), yang mangsanya adalah larva nyamuk. Selain itu, tanaman yang menimbulkan bau yang tidak disukai oleh nyamuk Aedes aegypti seperti akar wangi (vertiver zizanoides). Masyarakat diharapkan dapat menanam tanaman pengusir nyamuk di halaman rumah untuk menghindari berkembangbiaknya nyamuk vektor di sekitar rumah.

\section{f. Keberadaan Jentik}

Hasil penelitian menunjukkan bahwa keberadaan jentik positif di rumah responden sebesar $52,5 \%$ dan negatif sebesar 47,5\%. Bak mandi merupakan TPA yang paling banyak ditemukan jentik karena masyarakat jarang menguras bak mandi yang seharusnya dibersihkan minimal satu kali dalam satu minggu. Barang-barang bekas seperti ban bekas dan ember bekas masih banyak ditemukan berserakan di sekitar rumah masyarakat yang dapat menjadi tempat potensial untuk perkembangbiakan nyamuk vektor 
DBD yang sering diabaikan oleh masyarakat. Masyarakat tidak dapat mengubur barang bekas karena mereka beranggapan barang bekas masih dapat dijual sehingga ditumpuk di halaman rumah. Selain itu, tidak tersedianya lahan untuk mengubur barang bekas tersebut.

Hasil penelitian ini sejalan dengan penelitian Faridah (2017) di Kota Bandung bahwa bak mandi merupakan TPA yang paling banyak ditemukan larva nyamuk. Bak mandi merupakan TPA yang digunakan untuk keperluan sehari-hari sehingga umumnya memiliki volume yang cukup besar, dapat menyimpan cadangan air dalam waktu lama sehinga sangat potensial untuk menjadi tempat perkembangbiakan nyamuk.

Tempat berkembangbiak Aedes aegypti yang utama di dalam rumah adalah bak mandi, bak wc, tandon air minum, tempayan, gentong tanah liat, gentong plastik, ember, drum dan vas tanaman hias. Berdasarkan hasil survei jentik nyamuk yang telah dilakukan dapat diketahui angka kepadatan jentik yang disajikan dalam Tabel 1 berikut.

Tabel 1. Kepadatan populasi larva nyamuk (ABJ, HI, CI, BI) di Wilayah Kerja Puskesmas Air Dingin Kota Padang

\begin{tabular}{cccc}
\hline \multicolumn{4}{c}{ Indeks Kepadatan Vektor } \\
\hline ABJ & House Index & Container Index (CI) & Breteau Index (BI) \\
(Angka Bebas Jentik) & $($ HI) & & 81,8 \\
\hline $47,5 \%$ & 52,5 & 9,6 & 8 \\
\hline
\end{tabular}

Berdasarkan Tabel 1, menurut peneliti angka indeks kepadatan vektor yang tinggi disebabkan karena masih kurangnya partisipasi masyarakat dalam melaksanakan pengendalian vektor DBD dengan melakukan modifikasi lingkungan, manipulasi lingkungan, pengendalian secara fisik, pengendalian kimiawi, dan pengendalian secara biologis.

\section{Analisis Bivariat}

Pada penelitian ini analisis bivariat yang digunakan adalah uji Chi square, masing-masing variabel independen dan dependen yang sudah dikategorikan diuji apakah ada hubungan antara variabel independen modifikasi lingkungan, manipulasi lingkungan, dan pengendalian fisik dengan variabel dependen keberadaan jentik. Jika nilai $p<0,05$ maka Ho ditolak atau dengan kata lain hipotesis penelitian diterima.

\section{a. Hubungan Modifikasi Lingkungan dengan Keberadaan Jentik}

Hasil analisis statistik untuk mengetahui hubungan antara modifikasi lingkungan dengan keberadaan jentik dapat dilihat pada Tabel 2 di bawah ini.

Tabel 2. Hubungan Modifikasi dengan Keberadaan Jentik

\begin{tabular}{ccccccccc}
\hline \multirow{2}{*}{ No } & \multirow{3}{*}{ Modifikasi Lingkungan } & \multicolumn{6}{c}{ Keberadaan Jentik } & \multirow{2}{*}{ Nilai $\boldsymbol{p}$} \\
\cline { 2 - 8 } & & \multicolumn{2}{c}{ Positif } & \multicolumn{2}{c}{ Negatif } & \multicolumn{2}{c}{ Total } & \\
\cline { 2 - 8 } & f & \% & f & \% & F & \% & \\
\hline 1 & Buruk & 22 & $68,8 \%$ & 10 & $31,2 \%$ & 32 & $100 \%$ & \multirow{2}{*}{0,043} \\
\hline 2 & Baik & 30 & $44,8 \%$ & 37 & $55,2 \%$ & 67 & $100 \%$ & \\
\hline
\end{tabular}

Berdasarkan hasil tabulasi silang diketahui bahwa $p=0,043$, artinya $p<$ 0,05 maka dapat diambil kesimpulan bahwa ada hubungan antara modifikasi lingkungan dengan keberadaan jentik.
Modifikasi lingkungan yang baik dapat mengurangi tempat perindukan nyamuk, dan tentu saja akan mengurangi keberadaan jentik nyamuk Aedes aegypti. 
Beberapa cara modifikasi lingkungan yakni tempat penampungan air yang kecil - kecil supaya mudah untuk membersihkannya, memperbaiki talang rumah yang bocor, memperbaiki pipa aliran air yang bocor supaya tidak terjadi genangan air, merubah rawa - rawa menjadi perumahan atau kolam ikan, atau ditimbun untuk kegiatan lain, sehingga airnya tidak tergenang, dan dapat mengurangi tempat perindukan jentik Aedes aegypt.

Berdasarkan hasil wawancara dapat diambil kesimpulan bahwa kegiatankegiatan pencegahan melalui upaya modifikasi lingkungan dalam program pengendalian vektor DBD belum begitu tersosialisasi dengan baik, hal ini dapat dilihat dari angka penelitian yang menunjukkan masih adanya responden yang belum melakukan upaya penutupan atau pemanfaatan rawa-rawa yang ada dilingkungannya, hampir setengah responden menyatakan bahwa mereka tidak melakukan perbaikan got/ parit yang rusak untuk mengalirkan air yang tergenang. Selain itu masih ada juga responden yang mengaku belum mendapatkan informasi tentang program pengendalian vektor DBD.

Komunikasi dalam bentuk penyuluhan kesehatan merupakan kegiatan penting dalam meningkatkan partisipasi masyarakat sebagai salah satu bentuk perubahan perilaku. Faktor ini sangat berpengaruh terhadap penerimaan kebijakan program oleh kelompok sasaran, sehingga kualitas komunikasi tentunya akan mempengaruhi dalam mencapai efektivitas implementasi kebijakan program.

\section{b. Hubungan Manipulasi Lingkungan dengan Keberadaan Jentik}

Hasil analisis statistik untuk mengetahui hubungan antara manipulasi lingkungan dengan keberadaan jentik dapat dilihat pada Tabel 3 di bawah ini.

Tabel 3. Hubungan Manipulasi Lingkungan dengan Keberadaan Jentik

\begin{tabular}{|c|c|c|c|c|c|c|c|c|}
\hline \multirow{3}{*}{ No } & \multirow{3}{*}{ Manipulasi Lingkungan } & \multicolumn{6}{|c|}{ Keberadaan Jentik } & \multirow{3}{*}{ Nilai $p$} \\
\hline & & \multicolumn{2}{|c|}{ Positif } & \multicolumn{2}{|c|}{ Negatif } & \multicolumn{2}{|c|}{ Total } & \\
\hline & & $\mathbf{f}$ & $\%$ & $\mathbf{f}$ & $\%$ & $\mathbf{F}$ & $\%$ & \\
\hline 1 & Buruk & 36 & $62,1 \%$ & 22 & $37,9 \%$ & 58 & $100 \%$ & \multirow{2}{*}{0,040} \\
\hline 2 & Baik & 16 & $39 \%$ & 25 & $61 \%$ & 41 & $100 \%$ & \\
\hline
\end{tabular}

Berdasarkan hasil tabulasi silang diatas diketahui bahwa $p=0,040$, artinya $p<0,05$ maka dapat diambil kesimpulan bahwa ada hubungan antara manipulasi lingkungan dengan keberadaan jentik.Penelitian ini sejalan dengan penelitian Hadisaputro (2008) yang menyatakan bahwa ada hubungan kebiasaan membersihkan TPA dan kebiasaan menutup TPA yang merupakan bagian dari manipulasi lingkungan dengan keberadaan jentik di desa Katekan Kabupaten Grobogan tahun 2008, dan Damyanti (2008) di Kelurahan Genuksari Semarang, bahwa kebersihan lingkungan dengan melakukan $3 \mathrm{M}$, yang merupakan salah satu bentuk upaya manipulasi lingkungan berhubungan dengan keberadaan jentik Aedes aegypti.

Hasil pengamatan yang dilakukan oleh peneliti menunjukkan bahwa masih banyak barang - barang bekas yang dapat menampung air dibiarkan berserakan dan menumpuk di sekitar rumah penduduk. Berdasarkan hasil wawancara diketahui bahwa masih banyak responden yang tidak memanfaatkan barang bekas yang masih bisa terpakai untuk hal - hal yang berguna. Masyarakat juga kurang memperhatikan kebersihan pada wadah penampungan air, yang seharusnya dibuang setiap hari atau seminggu sekali. Bahkan masih ada juga masyarakat yang tidak memperhatikan kebersihan bak 
mandi, seperti melakukan pengurasan atau upaya lainnya. Semua keadaan ini tentu saja sangat mendukung munculnya keberadaan jentik di rumah mereka. Informasi terkait program pengendalian vektor dalam hal manipulasi lingkungan juga belum didapatkan secara spesifik oleh masyarakat baik dari petugas kesehatan di dinas kesehatan maupun puskesmas setempat.

Berdasarkan dari karakteristik responden juga dapat dilihat bahwa pendidikan responden juga dapat mempengaruhi keberhasilan program pengendalian vektor DBD, kebanyakan responden hanya tamatan SD $(30,3 \%)$ dan SMP $(39,4 \%)$, sehingga pengetahuan mereka tentang kesehatan terutama pengendalian tentang pengendalian vektor DBD hanya didapat sedikit saja jika dibandingkan jika mereka tamatan SMA atau perguruan tinggi. Mereka hanya mendapatkan pengetahuan dari media massa atau dari orang tua mereka yang terdahulu. Pekerjaan responden yang sebagian besar hanya sebagai ibu rumah tangga $(73,7 \%)$ juga menjadi salah satu penyebab kurangnya informasi yang mereka dapatkan, karena keterbatasan akses untuk mendapatkan informasi.

Pengelolaan lingkungan dengan cara manipulasi lingkungan dapat dilakukan melalui upaya Pemberantasan Sarang Nyamuk (PSN) yang pada dasarnya ialah pemberantasan jentik atau mencegah agar nyamuk tidak dapat berkembang biak. Untuk mencapai keberhasilan upaya PSN ini, maka perlu ditingkatkan kinerja kader jumantik dalam rangka melakukan pengawasan terhadap perilaku masyarakat dalam program pengendalian vektor DBD.

\section{c. Hubungan Pengendalian Fisik dengan Keberadaan Jentik}

Hasil analisis statistik untuk mengetahui hubungan antara pengendalian fisik dengan keberadaan jentik dapat dilihat pada Tabel 4 di bawah ini.

Tabel 4. Hubungan Pengendalian Fisik dengan Keberadaan Jentik

\begin{tabular}{ccccccccc}
\hline \multirow{2}{*}{ No } & \multirow{2}{*}{ Pengendalian Fisik } & \multicolumn{6}{c}{ Keberadaan Jentik } & \multirow{2}{*}{ Nilai $\boldsymbol{p}$} \\
\cline { 3 - 8 } & & \multicolumn{2}{c}{ Positif } & \multicolumn{2}{c}{ Negatif } & \multicolumn{2}{c}{ Total } & \\
\cline { 2 - 8 } & f & \% & f & \% & F & \% & \\
\hline 1 & Buruk & 21 & $70 \%$ & 9 & $30 \%$ & 30 & $100 \%$ & \multirow{2}{*}{0,038} \\
\hline 2 & Baik & 31 & $44,9 \%$ & 38 & $55,1 \%$ & 69 & $100 \%$ & \\
\hline
\end{tabular}

Berdasarkan hasil tabulasi silang di atas diketahui bahwa $p=0,038$, artinya $p<$ 0,05 maka dapat diambil kesimpulan bahwa ada hubungan antara pengendalian fisik dengan keberadaan jentik.Hasil penelitian ini sejalan dengan penelitian Lisdawati (2012) bahwa terdapat hubungan antara pengendalian fisik dengan keberadaan jentik Aedes aegypti di Kelurahan Bagan Deli Belawan. Masyarakat di Kelurahan Bagan Deli Belawan hanya sebagian kecil yang menggunakan kawat kasa nyamuk, banyak pakaian yang tergantung serta sedikit yang melakukan scrining nyamuk.

Berdasarkan hasil pengamatan peneliti bahwa masyarakat di Wilayah
Kerja Puskesmas Air Dingin kurang melakukan upaya pengendalian secara fisik, hal ini terlihat dari hasil jawaban kuesioner yang masih banyak sekali menyatakan kebiasaan mereka menggantung pakaian di dalam rumah, serta sedikit sekali dari mereka yang melakukan upaya skrining nyamuk, hal ini disebabkan karena kurangnya perhatian mereka terhadap penyakit DBD dan kurangnya informasi yang didapat tentang program pengendalian vektor DBD.

Oleh sebab itu, diharapkan sekali partisipasi masyarakat untuk pengendalian secara fisik dengan melakukan scrining nyamuk setiap hari di tempat - tempat yang disukai oleh nyamuk yaitu daerah 
yang gelap dan bertumpuknya barang barang bekas yang dapat menampung air, dan pakaian yang tergantung. Pengendalian secara fisik ini jika dilakukan dengan baik tentu saja akan dapat mengurangi kepadatan jentik nyamuk yang nantinya akan berkembangbiak menjadi vektor dan berperan sangat besar dalam proses penularan penyakit DBD.

\section{d. Hubungan Pengendalian Kimiawi dengan Keberadaan Jentik}

Hasil analisis statistik untuk mengetahui hubungan antara pengendalian kimiawi dengan keberadaan jentik dapat dilihat pada Tabel 5 berikut.

Tabel 5. Hubungan Pengendalian Kimiawi dengan Keberadaan Jentik

\begin{tabular}{|c|c|c|c|c|c|c|c|c|}
\hline \multirow{3}{*}{ No. } & \multirow{3}{*}{ Pengendalian Kimiawi } & \multicolumn{6}{|c|}{ Keberadaan Jentik } & \multirow{3}{*}{ Nilai $p$} \\
\hline & & \multicolumn{2}{|c|}{ Positif } & \multicolumn{2}{|c|}{ Negatif } & \multicolumn{2}{|c|}{ Total } & \\
\hline & & $\mathbf{f}$ & $\%$ & f & $\%$ & f & $\%$ & \\
\hline 1 & Buruk & 46 & 59,0 & 32 & 41,0 & 78 & 100,0 & \multirow{3}{*}{0,026} \\
\hline 2 & Baik & 6 & 28,6 & 15 & 71,4 & 21 & 100,0 & \\
\hline & Jumlah & 52 & 52,5 & 47 & 47,5 & 99 & 100,0 & \\
\hline
\end{tabular}

Berdasarkan hasil uji statistik menggunakan uji chi-square diperoleh $p$ value sebesar $0,026 \quad(\mathrm{p}<0,05)$ berarti terdapat hubungan antara pengendalian kimiawi dalam program pengendalian vektor DBD dengan keberadaan jentik di Wilayah Kerja Puskesmas Air Dingin Kota Padang tahun 2018.

Hasil penelitian ini sejalan dengan penelitian Lisdawati (2012) di Kelurahan Bagan Deli bahwa pemberian abate dan fogging dapat menurunkan angka bebas jentik. Masyarakat di Kelurahan Bagan Deli berpartisipasi dalam prmberian abate pada tempat penampungan air. Akan tetapi jika persediaan abate habis masyarakat tidak meminta kembali kepada petugas, sehingga keberadaan jentik masih tinggi.

Pengendalian vektor DBD secara kimiawi adalah pengendalian nyamuk dewasa melalui fogging menggunakan malathion serta abatisasi dengan temephos yang dipalikasikan dalam pengendalian jentik. Temephos (abate) telah direkomendasikan penggunaannya oleh WHO sejak tahun 1970 untuk pengendalian larva Aedes dan aman bila digunakan pada air minum (Salim, 2011).

Berdasarkan hasil penelitian, masyarakat di wilayah kerja Puskesmas
Air Dingin masih kurang berpartisipasi dalam pengendalian vektor DBD terutama dalam upaya pengendalian kimiawi. Hal ini terlihat dari jawaban kuesioner sebagian besar tidak menggunakan bubuk abate untuk menghindari perkembangbiakan jentik nyamuk di dalam TPA. Selain itu masyarakat tidak sepenuhnya brpartisipasi ketika ada petugas kesehatan yang melakukan fogging, masyarakat tidak mau asap dari kegiatan fogging masuk ke dalam rumah mereka. Selain itu, masih rendahnya kemauan masyarakat untuk menggunakan obat anti nyamuk baik semprot, bakar atau oles. Penggunaan bahan kimia dalam pengendalian vektor harus memperhatikan petunjuk dan cara penggunaan untuk menghindari timbulnya bahaya keracunan pada manusia ataupun resistensi terhadap vektor.

Oleh karena itu, peran petugas kesehatan sangat diperlukan untuk mensosialikan pengendalian vektor DBD secara kimiawi seperti penggunaan obat anti nyamuk, peningkatan partisipasi dalam kegiatan fogging, dan penggunaan bubuk abate yang tepat.

\section{e. Hubungan Pengendalian Biologis dengan Keberadaan Jentik}


Hasil analisis statistik untuk pengendalian kimiawi dengan keberadaan mengetahui hubungan antara jentik dapat dilihat pada Tabel 6 berikut.

Tabel 6. Hubungan Pengendalian Biologis dengan Keberadaan Jentik

\begin{tabular}{lllllllll}
\hline No. Pengendalian Biologis & \multicolumn{6}{c}{ Keberadaan Jentik } & \multirow{2}{*}{ Nilai $\boldsymbol{p}$} \\
\cline { 3 - 8 } & & & Positif & \multicolumn{3}{c}{ Negatif } & Total & \\
\cline { 3 - 7 } & & f & \% & f & \% & f & \% & \\
\hline 1 & Buruk & 24 & 68,6 & 11 & 31,4 & 35 & 100,0 & \multirow{2}{*}{0,031} \\
2 & Baik & 28 & 43,8 & 36 & 56,3 & 64 & 100,0 & 0,03 \\
\hline & Jumlah & 52 & 52,5 & 47 & 47,5 & 99 & 100,0 & \\
\hline
\end{tabular}

Berdasarkan hasil uji statistik menggunakan uji chi-square diperoleh $p$ value sebesar $0,031 \quad(\mathrm{p}<0,05)$ berarti terdapat hubungan antara pengendalian biologi dalam program pengendalian vektor DBD dengan keberadaan jentik di Wilayah Kerja Puskesmas Air Dingin Kota Padang tahun 2018. Hasil penelitian ini sejalan dengan penelitian Widiastuti (2010) dalam Lisdawati (2012) di Semarang yang menyatakan bahwa ada hubungan pemeliharaan ikan yang merupakan salah satu pengendalian biologi dengan keberadaan jentik Aedesaegypti di Kota Semarang.

Menurut Wihartyas (2015), pemberian ikan mas terbukti efektif dalam menurunkan larva nyamuk. Kemampuan makan ikan cupang (Betta spp) lebih tinggi dibandingkan dengan ikan nila (Oreochromis niloticus) dan ikan mas (Cyprinus carpio) dengan jumlah larva yang dimakan 34,6 - 36,9 ekor larva nyamuk. Dengan demikian, partisipasi masyarakat sangat diharapkan dalam pencegahan perkembangbiakan vektor secara biologi dengan memelihara ikan pemakan jentik di tempat penampungan air di dalam atau di luar rumah.

\section{KESIMPULAN}

Terdapat hubungan yang siginifikan antara variabel modifikasi lingkungan, manipulasi lingkungan, pengendalian fisik, pengendalian kimiawi, pengendalian biologi dengan keberadaan jentik dalam program pengendalian vektor DBD. Oleh sebab itu, perlu adanya peningkatan kerjasama lintas sektoral serta melakukan KPP melalui pembentuk dan peningkatan peran aktif kader jumantik, pemberian pelatihan dan pencerahan kepada petugas kesehatan dan kader, serta pengawasan yang rutin dan tepat waktu terhadap seluruh rangkaian kegiatan program penanggulangan DBD. Selain itu pemerintah setempat juga perlu mengeluarkan kebijakan dalam rangka menggalakkan kegiatan program penanggulangan DBD.

\section{UCAPAN TERIMA KASIH}

Ucapan terimakasih penulis sampaikan kepada Direktorat Pendidikan Tinggi yang telah membiyai penelitian ini melalui program hibah Penelitian Dosen Pemula.

\section{DAFTAR PUSTAKA}

Adrianto, H., Subagyo, Y., \& Hamidah. (2014). Efektivitas Ekstrak Daun Jeruk Purut (Citrus hystrix), Jeruk Limau (Citrus amblycarpa), dan Jeruk Bali (Citrus maxima) terhadap Larva Aedes aegypti. Jurnal Aspirator, 6(1): 1-6.

Damyanti, R. (2008). Hubungan Pengetahuan, Sikap, dan Praktek 3M dengan Keberadaan Jentik Aedes aegypti pada Daerah Endemis Demam Berdarah 
Dengue di Kelurahan Kepolorejo Kecamatan Magetan Kabupaten Magetan 2008. Skripsi. Universitas Diponegoro, Semarang.

Dinas Kesehatan Kota Padang. (2016). Profil Kesehatan Kota Padang 2016. Dinkes Kota Padang, Padang.

Faridah, L., Respati, T., Sudigdoadi, S., \& Sukandar, H. (2017). Gambaran Partisipasi Masyarakat terhadap Pengendalian Vektor Melalui Kajian Tempat Perkembangbiakan Aedes aegypti di Kota Bandung. Jurnal MKB, 49 (1).

Hadisaputro, L.I. (2012). Faktor-Faktor Lingkungan Tempat Penampungan Air (TPA) yang Berhubungan dengan Keberadaan Jentik Nyamuk Aedes Aegypti di Desa Katekan Kabupaten Grobongan Tahun 2008. Jurnal Kesehatan UMS, 5 (1).

Kementerian Kesehatan RI. (2016). Profil Kesehatan Indonesia 2016. Kemenkes RI, Jakarta.

Lisdawati. (2012). Pengaruh Partisipasi Masyarakat dan Program Pengendalian DBD yang Dilakukan Oleh Kantor Kesehatan Pelabuhan Kelas I Medan Terhadap Keberdaan Jentik Aedes aegypti di Kelurahan Bagan Deli Belawan Tahun 2012. Tesis. FKM USU, Medan.

Mulyatno K.C., Yamanaka, A., Ngadino, \& Konishi, E. (2012). Resistance of Aedes aegypti to Temephos in Surabaya, Indonesia. Shoutheast Asian Journal Tropical Medicine Public Health, 43(1): 29-33.

Prasetyowati, H., Santya, R.N.R.E., \& Nurindra, R.W. (2015). Motivasi dan Peran Serta Masyarakat Dalam Pengendalian Populasi Aedes Spp Di Kota Sukabumi. Jurnal Ekologi Kesehatan, 14(2):106-115.

Salim, M., Ambarita, L. P., Yahya, Yenni, A., \& Supranelfy, Y. (2011). Aktivitas Malathion dalam Pengendalian Vektor DBD dan Uji Kerentanan Larva Aedesaegypti terhadap Temephos di Kota Palembang. Jurnal Buletin Penelitian Kesehatan, 39 (1): 10-21.

Syatriani, S., Puji, E., \& Susilowati, A. (2009). Partisipasi Masyarakat Menanggulangi Lingkungan Demam Berdarah Dengue di Kecamatan Rappocini Kota Makassar. Jurnal Kesmas National Public Health, 3(5).

Tairas, S., Kandou, G.D., \& Posangi, J. (2015). Analisis Pelaksanaan Pengendalian Demam Berdarah Dengue di Kabupaten Minahasa Utara. JIKMU, 5(1).

Wihartyas, VF. (2015). Efektivitas Pemberian Ikan Mas (Cyprinus carpio) dalam Menurunkan Jumlah Larva dan Persepsi Masyarakatnya (Studi Kasus Di Rw 06 Kelurahan Sukorejo Kecamatan Gunungpati Kota Semarang. Skripsi. Universitas Negeri Semarang, Semarang. 